\title{
To Study the Microbial Agents, Including Bacteria and Yeasts Responsible for UTI in western Uttar Pradesh Population India
}

\author{
Rama Nand Singh* \\ Mulayam Singh Yadav Medical College, Meerut, Uttar Pradesh, India \\ *Corresponding author
}

\section{A B S T R A C T}

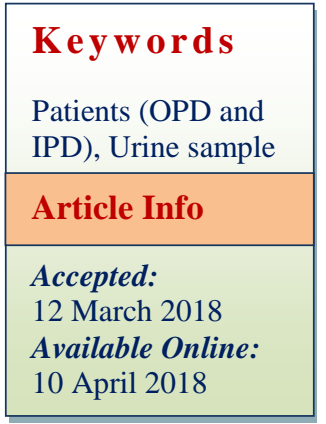

Urinary tract infection (UTI) is a very common infection both in the community and hospital patients. UTI's rank second only to respiratory infections in their incidence. Common etiological agents are Bacteria including most common Escherichia Coli, fungus Candida. Aim is to Study the Microbial Agents, Including Bacteria \& Yeasts Responsible for UTI in Patient attending Both OPD and IPD at Santosh Medical College and Hospital Ghaziabad. To Study the Antimicrobial Sensitivity Patterns of bacterial Uropathogens. A total of 300 patients were included for the present study. Their age group ranged from 15 to 45 years of age. Adopted for identification Sample collection, Urine Analysis Wet mount preparation GRAM STAINING, isolation on CLED AGAR, BLOOD AGAR, method and biochemical reaction was done. The most common isolated organism is $E$. coli and Candida was isolated. $15 \%$.

\section{Introduction}

Urinary tract infection (UTI) is a very common infection both in the community and hospital patients and ranks high amongst the most common reasons that compel a patient to seek medical attention (Gastmeier et al., 1998).

Acute UTIs are associated with substantial morbidity and problems of recurrent infections. Studies have shown that approximately $25 \%$ of women with first UTI will have another attack within 6 Months. A mounting of body of evidence indicates that UTI is responsible for a large proportion of antibiotic consumption in and out of the hospital. No wonder that the infection has a large socio - economic impact and contributes to the emergence of antibiotic resistance in the hospital and the community (Magee et al., 1996).

Urinary tract infection (UTI) is a very common infection both in the community and hospital patients and ranks high amongst the most common reasons that compel a patient to seek medical attention Acute UTIs are associated with substantial morbidity and problems of recurrent infections (Foxman, 1990).

Several studies in the past have shown that Escherichia coli is the most common etiological agent of the UTI in hospital and community patients and that hospital- 
acquired UTI, in particular, is characteristically associated with a higher prevalence of enterococci and coagulase negative Staphylococci (CNS) (Jones et al., 1999).

It was observed that out of 2,379 uropathogens Escherichia coli $(66.92 \%)$ was the most prevalent isolate followed by Klebsiella spp. (13.45\%), Proteus spp. (6.77\%) and Pseudomonas spp. (6.77\%) (Jadav et al., 2004). To optimize the use of empiric antibiotic therapy for UTI, it is important for clinicians to have a working knowledge of the etiological agents and the susceptibility patterns of UTI pathogens in their populations (Vorland et al., 1985).

Since uropathogens and their susceptibility may vary from time to time and from one institution to another, each hospital or institution must have its own evaluation for such infection so that any change in the causative agents and susceptibility pattern can be detected and managed accordingly (Gupta et al., 1999).

\section{Materials and Methods}

Urine samples were collected from patients attending the Outpatient Department and admitted in department of general medicine at Santosh Medical College and Hospital, Ghaziabad urine samples from patient showing presumptive symptoms of UTI were collected and processed.

\section{Exclusion criteria}

Cases with hypertension

Cases with tuberculosis

Cases with sexually transmitted disease and HIV

\section{Inclusion criteria}

Patient of all age groups and both sexes.

Symptomatic patient suspecting urinary tract infection.

Catheterized patient.

\section{Sample collection}

Clean-Catch sample to obtain an untainted urine sample midstream (MSU), or cleancatch, urine sample. To provide this, the following steps are taken: Patients must first wash their hands thoroughly, then wash the penis or vulva and surrounding area four times, with front-to-back strokes, using a new soapy sponge each time.

The patient must then begin urinating into the toilet and stop after a few ounces.

The patient then positions the container to catch the middle portion of the stream. Ideally, this urine will contain only the bacteria and other evidence of the urinary tract infection.

The patient then urinates the remainder into the toilet.

The patient securely screws the container cap in place without touching the inside of the rim.

\section{Interpretation}

Gram-Negative bacteria - E. coli, Salmonella, Pseudomonas, Moraxella, Helicobacter, Stenotrophomonas, Legionella Hemophilus influenzae, Neisseria Meningitidis, Moraxella Catarrhalis, Neisseria, Gonorrhoeae, Acinetobacter baumanni Gram positive bacteria - Staphylococcus, Streptococcus, Enterococcus, and Bacillus, Corynebacterium, Nocardia, Clostridium, Actinobacteria, and Listeria. 


\section{KOH}

The potassium hydroxide test is a procedure in which potassium hydroxide $(\mathrm{KOH})$ is used to detect fungi by dissolving human cells in a culture.

The difference in cell wall composition of human cells and fungal cells allows this procedure to help distinguish the two cells. $\mathrm{KOH}$ denatures the proteins in the human cell; only the fungal cells remain to be seen under the microscope.

\section{$\mathrm{KOH}$ test procedure:}

Take scraping from margin (not center) of the lesion

Place on a clean slide

Add 2-3 drops of $10 \% \mathrm{KOH}$ in water

Warm the slide (don't boil)

Optional - add 1 drop of lactophenol cotton blue

Add cover slip

Examine immediately under high, dry magnification with light microscope

\section{Culture}

Semiquantitative culture. A semiquantitative plate counts as described by Barry et al., was used as the reference method.

\section{The method followed is as follows}

Mix the urine sample thoroughly and remove the top of the container.

Flame a calibrated wire inoculating loop (inside diameter of $4 \mathrm{~mm}$ ) and allow it to cool without touching any surface. Insert this sterile loop in the urine sample vertically and allows urine to adhere to the loop.

Spread the loopful of urine over the CLED AGAR plate using standard method.

In the similar way, collect a second loopful specimen and inoculate a blood agar plate.

$3^{\text {rd }}$ loopful is put on the SDA culture slope

Incubate the plates aerobically at $35-37$ oc for at least 24 hours. Count the colonies and count the cfu s (colony forming unit) by multiplying with 100 (since $0.01 \mathrm{ml}$ loop was used, (Hasman et al., 2005).

\section{Interpretation: clean voided specimen}

Normal: $<10,000$ organisms per $\mathrm{ml}$ Urinary tract infection

Boys

Organisms $>10,000$ per $\mathrm{ml}$ suggests UTI likely

Girls

Organisms $>100,000$ per ml suggests UTI

Three specimens: $95 \%$ probability of UTI

Two specimens: $90 \%$ probability of UTI

One specimen: $80 \%$ probability of UTI

Organisms $>10,000$ per $\mathrm{ml}$ needs repeat urine culture

Interpretation:

transurethral catheterization

Normal: $<1,000$ organisms per $\mathrm{ml}$ Urinary Tract Infection

Organisms $>10,000$ per ml suggests UTI 
Organisms $>1,000$ per $\mathrm{ml}$ needs repeat urine culture

Interpretation: suprapubic aspiration in infants

Gram Negative Bacilli: any number suggests UTI $(99 \%)$

Gram Positive Cocci: >1-2,000 suggests UTI $(99 \%)$

\section{CLED AGAR}

\section{Principle}

CLED AGAR is a non-selective differential plating medium for the growth and enumeration of urinary tract microorganisms. Omitting sodium chloride inhibits the Proteus swarming and supports the growth of the vast majority of bacteria causing urinary tract infections, and is used to differentiate and identify them.

\section{Procedure}

The microorganisms which cause infection in the urinary tract are generally abundant and of only one species. E. coli is the organism most frequently isolated. The seeding of the sample can be done by the dilute on method or by streaking on the surface of agar with a calibrated loop. Count the colonies after 24-48 hours of incubation at a temperature of $35 \pm$ $2^{\circ} \mathrm{C}$. Report the number of colonies per $\mathrm{ml}$ of urine. A count of $100.000(105) / \mathrm{ml}$ or more is an indication of a significant clinical urinary tract infection.

\section{Blood agar}

Suspend $40 \mathrm{~g}$ in 1 litre of distilled water. Bring to a boil to dissolve completely. Sterilize by autoclaving at $121^{\circ} \mathrm{C}$ for 15 minutes. For blood agar, cool to $45-50^{\circ} \mathrm{C}$ and add aseptically $6 \%(5-10 \%$ is typically) of sterile defibrinated blood.

\section{Principle and Interpretation}

Blood Agar Base formulation has been used as a base for the preparation of blood agar and to support good growth of a wide variety of fastidious microorganisms. Because it is a highly nutritious medium it can also be used as a general purpose growth media without adding blood. For example it was used for studying irradiated Escherichia coli. Meat extract and Peptone provide nitrogenous compounds, vitamins, carbon, sulphur and amino acids in Blood Agar Base. The medium contains sodium chloride for the osmotic balance. Blood Agar Bases are relatively free of reducing sugars, which have been reported to adversely influence the hemolytic reactions of beta-hemolytic streptococci. Sheep blood gives best results for Group A Streptococci.

\section{SDA colony}

Gram stain like all fungal media, SDA contains sources of carbon, nitrogen and vitamins. SDA contains the sugar glucose, for carbon, and neopeptone and polypeptone agar (a solidifying agent) for nitrogen. The finished media has a pH of 5.6, which is mildly acidic.

A commercially available form from Conda Pronadisa has a slightly different formulation, using glucose, agar and a mixture of "peptic digest of animal tissue and pancreatic digest of casein." This animal tissue provides the nitrogen and vitamin source that the organisms require.

\section{Candida albicans - Creamy. pasty colony}

\section{Interpretation of results}

Bacteria that ferment any of the three sugars in the medium will produce byproducts. 
Chart.1 Proportion of urine samples received in the lab from indoor and outdoor patients

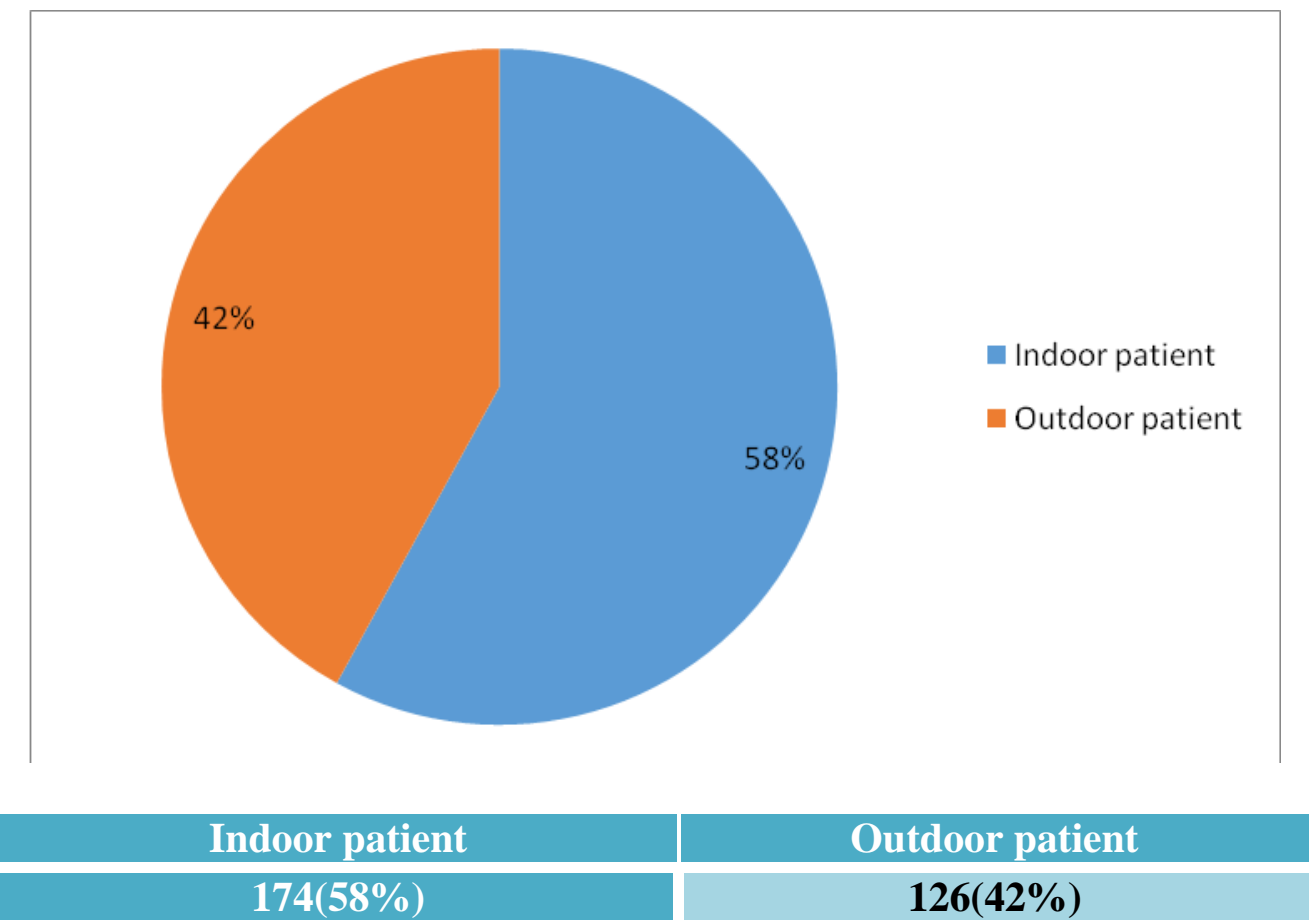

Chart.2 Proportion of urine samples from indoor and outdoor patients with and without growth of pathogen

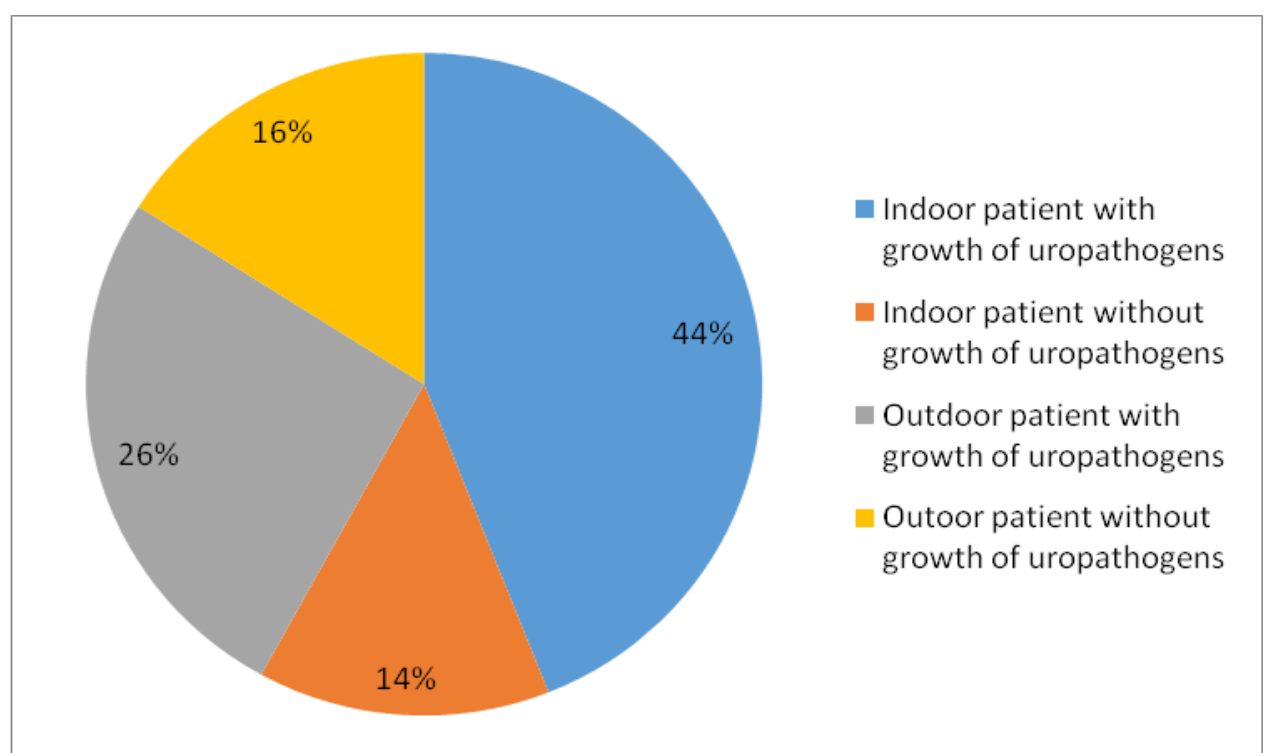

\begin{tabular}{|c|c|c|c|}
\hline $\begin{array}{c}\text { Indoor patient with } \\
\text { growth of } \\
\text { uropathogens }\end{array}$ & $\begin{array}{c}\text { Indoor patient } \\
\text { without growth of } \\
\text { uropathogens }\end{array}$ & $\begin{array}{c}\text { Outdoor patient with } \\
\text { growth of } \\
\text { uropathogens }\end{array}$ & $\begin{array}{c}\text { Outoor patient } \\
\text { without growth of } \\
\text { uropathogens }\end{array}$ \\
\hline$(44 \%) 132$ & $\mathbf{4 2 ( 1 4 \% )}$ & $\mathbf{7 8}(\mathbf{2 6 \%})$ & $\mathbf{4 8}(\mathbf{1 6 \%})$ \\
\hline
\end{tabular}


Chart.3 Types of uropathogenis organism isolated from outdoor patients

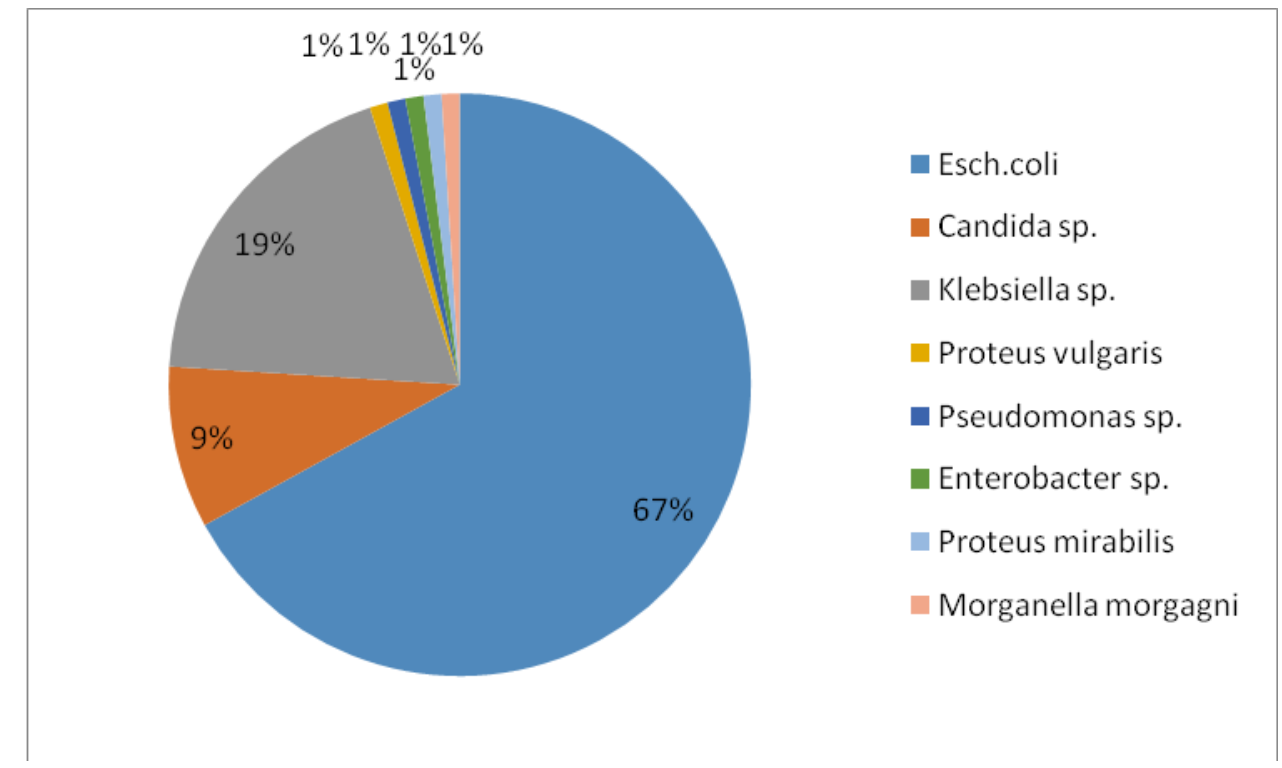

\begin{tabular}{|c|c|c|c|c|c|c|c|}
\hline E. coli & $\begin{array}{c}\text { Candida } \\
\text { sp. }\end{array}$ & $\begin{array}{c}\text { Klebsiella } \\
\text { sp. }\end{array}$ & $\begin{array}{c}\text { Proteus } \\
\text { vulgaris }\end{array}$ & $\begin{array}{c}\text { Pseudomonas } \\
\text { sp. }\end{array}$ & $\begin{array}{c}\text { Enterobacter } \\
\text { sp. }\end{array}$ & $\begin{array}{c}\text { Proteus } \\
\text { mirabilis }\end{array}$ & $\begin{array}{c}\text { Morganella } \\
\text { morgagni }\end{array}$ \\
\hline$(67 \%)$ & $(\mathbf{9 \%})$ & $(\mathbf{1 9 \%})$ & $(\mathbf{1 \%})$ & $(\mathbf{1 \%})$ & $\mathbf{( 1 \% )}$ & $\mathbf{( 1 \% )}$ & $\mathbf{( 1 \% )}$ \\
84 & $\mathbf{1 1}$ & $\mathbf{2 4}$ & $\mathbf{1 2}$ & $\mathbf{1 2}$ & $\mathbf{1 2}$ & $\mathbf{1 2}$ & $\mathbf{1 2}$ \\
\hline
\end{tabular}

Chart.4 Types of uropathogenic organisms isolated from indoor patient

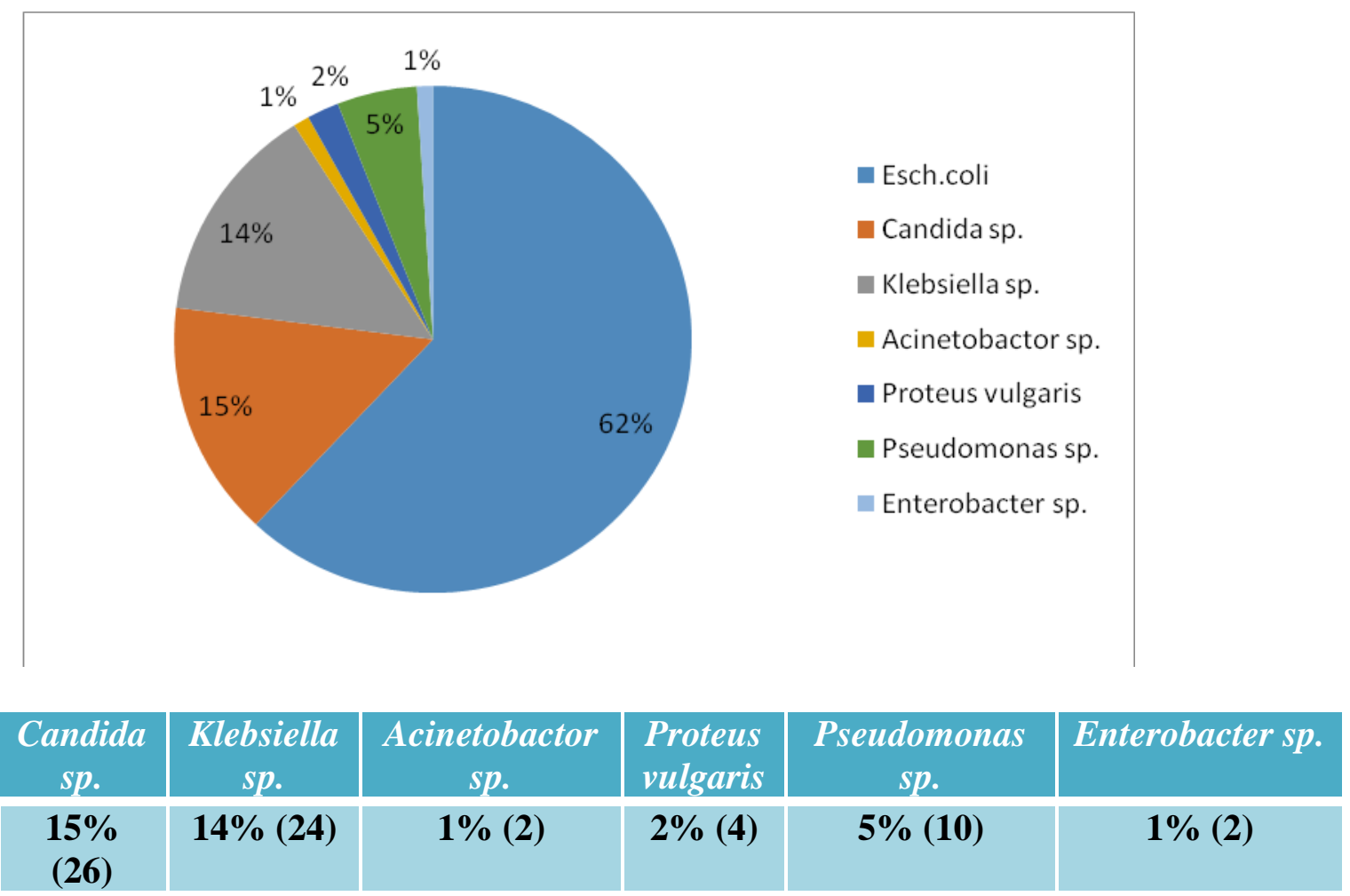


These byproducts are usually acids, which will change the color of the red $\mathrm{pH}$-sensitive dye (phenol red) to a yellow color. Position of the color change distinguishes the acid production associated with glucose fermentation from the acidic byproducts of lactose or sucrose fermentation. Many bacteria that can ferment sugars in the anaerobic butt of the tube are enterobacteria. Some bacteria utilize thiosulfate anion as a terminal electron acceptor, reducing it to sulfide. If this occurs, the newlyformed hydrogen sulfide $\left(\mathrm{H}_{2} \mathrm{~S}\right)$ reacts with ferrous sulfate in the medium to form ferrous sulfide, which is visible as a black precipitate. Examples of sulfide-producing bacteria include Salmonella, Proteus, Citrobacter and Edwardsiella species.

The blackening of the medium is almost always observed in the butt (bottom) of the medium. All lactose fermenters result in yellow slant/yellow butt (acid/acid reaction), whereas non-lactose fermenters may result in pink/yellow or yellow/yellow (if sucrose is fermented). Blackening of the butt due to $\mathrm{H}_{2} \mathrm{~S}$ production may mask the acid reaction (yellow) in the butt. Salmonella enterica serovar Typhi may result in blackening of the medium at the interface of butt and slant.

\section{For yeast}

Sabouraud Dextrose AGAR W/ Chloramphenicol Intended use SDA plates were incubated at $26 \pm 1^{\circ} \mathrm{C}$ to enhance the growth of fungi, and the remaining plates were incubated at $36 \pm 1^{\circ} \mathrm{C}$ Primary isolation and other two were compared with it.

\section{Results and Discussion}

A total of 300 patients were included for the present study. Their age group ranged from 15 to 45 years of age.

Proportion of urine samples received in the laboratory from indoor pt. was 174 (58\%) and outdoor pt. was 126 (42\%) (chart no-1). Number of indoor patients showing growth of uropathogens were 132 (44\%) and outdoor pt with growth of uropathogen were $78(26 \%)$ (Chart no-2).

Among out door patients commonest uropathogens isolated was E. coli 84 (67\%) followed by Candida sp. (9\%), Klebsiella sp. (19\%), Proteus (1\%), Pseudomonas sp. (1\%), Enterobacter sp. (1\%), Proteus mirabilis (1\%) (Chart No.-3, 4).

A total number of 300 urine samples from OPD and IPD patient of Santosh Medical College and Hospital were processed. Out of these samples 240 urine samples shows growth of uropathogens, highest number was $E$. coli (61.9\%), Klebsiella (16.1\%), and Candida $(12.3 \%)$. that $E$. coli is the most common isolates is well known fact and is evidence form different studies. in a study conducted at Apollo hospital Delhi, India (Bal, 2006) E. coli was the most prevalent uropathogen $(61 \%)$ followed by Klebsiella $(22 \%) 56.6 \%$ of uropathogens isolates were from indoor patient and rest $43.4 \%$ were from outdoor patient. among the patients hospitalized with UTI.

The usual isolation rate of uropathogens in this study used to be $22.7 \%$ which is notably decrease than the quotes mentioned from Ethiopia and Nigeria (Biadglegne et al., 2009), (El-Mahmood et al., 2009). However, the charge was higher than different studies (Kashef et al., 2010; Beyene et al., 2011; Demile et al., 2012). E. coli was once the most predominant bacterium reported from urine, observed via Klebsiella spp., Proteus spp., Pseudomonas spp., CNS, S. aureus, Enterobacter spp. and Citrobacter spp. The isolation rates of E. coli and different pathogens in this study were similar to the prices documented in the past (Demile et al., 2012; De Francesco et al., 2007). Bacterial etiologies of UTI can show geographic versions and may even range over time within a populace (Demile et al., 2012; ElMahmood et al., 2009).

A substantial percentage of hospitalized patients had nosocomial UTI. E. coli I was found to be 
the most common urinary isolate both from inpatient and outpatient. There was a high proportion of ESBL production strain among the uropathogenic $E$. coli isolates in the present study.

\section{References}

Beyene G, Tsegaye W. Bacterial uropathogens in urinary tract infection and antibiotic susceptibility pattern in Jimma University Hospital, Ethiopia. Ethiop J Health Sci. 2011; 21:141-146.

Biadglegne F, Abera B. Antimicrobial resistance patterns of bacterial isolates from urinary tract infections at Felege Hiwot Hospital, Ethiopia. Ethiop J Health Dev. 2009; 23:236-238.

De Francesco MA, Giuseppe R, Laura P, Riccardo N, Nino M. Urinary tract infections in Brescia, Italy: Etiology of uropathogens and antimicrobial resistance of common uropathogens. Med Sci Monit. 2007; 13:136-144.

Demile T, Beyene G, Melaku S, Tsegaye W. Urinary bacterial profile and antibiotic susceptibility pattern among pregnant women in North West Ethiopia. Ethiop J Health Sci. 2012; 22:121-128.

El-Mahmood AM, Atimi AT, Tirmidhi B, Mohammed A. Antimicrobial susceptibility of some quinolone antibiotics against some urinary tract pathogens in a tertiary hospital, Yola, Adamawa State, Nigeria. J Clin Med Res. 2009; 1:26-34.

Foxman B: Recurring urinary tract infection: incidence and risk factors. Am J Public Health 1990; 80: 331.

Gastmeier P, Kampf G, Weschnewski N, Hauer T, Schulgen G, Schumacher M, Daschner F, Ruden H: Prevalence of nosocomial infections in representative German hospitals. J Hosp Infect 1998; 38: 37-49.

Gupta K, Hooton TM, Wobbe CL, Stamm WE: The prevalence of antimicrobial resistance among uropathogens causing acute uncomplicated cystitis in young women. Int J Antimicrob Agents 1999; 11: 305-308.

Hasman H, Mevius D, Veldman K, Olesen I, Aarestrup FM. $\beta$-Lactamases among extended-spectrum $\beta$-lactamase (ESBL)resistant Salmonella from poultry, poultry products and human patients in The Netherlands. J. Antimicrob. Chemother. 2005; 56(1):115-21.

Jadav, Surangi K., Patel, K. C., Jain, Usha, Dastur, F. D. and Acharya, Vidya N.: Dip-slide method in the diagnosis of UTI. J. Assoc. Phys. India, 22: 255-259, 1974

Jones RN, Kugler KC, Pfaller MA, Winokur PL, SENTRY Surveillance Group: Characteristics of pathogens causing urinary tract infections in hospitals in North America: results from the SENTRY Antimicrobial Surveillance Program, 1997. Diagn Microbiol Infect Dis 1999; 35: 55-63.

Kashef N, Djavid GE, Shahbazi S. Antimicrobial susceptibility patterns of community-acquired uropathogens in Tehran, Iran. J Infect Dev Ctries. 2010; 4:202-206. [PubMed]

Magee JT, Pritchard EL, Fitzgerald KA, Dunstan FDJ, Howard AJ: Antibiotic prescribing and antibiotic resistance in community practice: retrospective study, 1996-1998. BMJ 1999; 319: 1239-1240.

Vorland LH, Carlson K, Aalen O: An epidemiological survey of urinary tract infections among outpatients in Northern Norway. Scand J Infect Dis 1985; 17: 277-283.

\section{How to cite this article:}

Rama Nand Singh. 2018. To Study the Microbial Agents, Including Bacteria and Yeasts Responsible for UTI in western Uttar Pradesh Population India. Int.J.Curr.Microbiol.App.Sci. 7(04): 1652-1659. doi: https://doi.org/10.20546/ijcmas.2018.704.186 